\title{
Ocorrência e significado do toque entre profissionais de enfermagem e pacientes de uma UTI e Unidade Semi-intensiva cirúrgica
}

\author{
OCCURENCE AND MEANING OF THE TOUCH BETWEEN NURSING PROFESSIONALS AND PATIENTS OF \\ AN ICU AND SEMI INTENSIVE SURGICAL UNIT
}

\section{OCURRENCIAY SIGNIFICADO DEL TOQUE ENTRE PROFESIONALES DE ENFERMERÍA Y PACIENTES DE UNA UCIY UNIDAD SEMIINTENSIVA QUIRÚRGICA}

\section{Marília Fogaça Galaํ, Sandra Cristina Ribeiro Telles², Maria Júlia Paes da Silva ${ }^{3}$}

1 Aluna do Curso de graduação da Escola de Enfermagem da Universidade de São Paulo

2 Enfermeira. Chefe de Seção da Unidade de Terapia Intensiva da Clínica Cirúrgica do Hospital Universitário da Universidade de São Paulo

3 Professora Livre Docente do Departamento de Enfermagem Médico-Cirúrgico da Escola de Enfermagem da Universidade de São Paulo.

juliaps@usp.br

\author{
RESUMO \\ Este trabalho tem como \\ objetivos identificar a \\ utilização, pelos \\ profissionais de \\ Enfermagem, do toque \\ instrumental elou afetivo e \\ suas características, na \\ comunicação não-verbal com \\ os pacientes da UTI e \\ unidade semi-intensiva \\ cirúrgica do HU-USP; e os \\ sentimentos e percepções dos \\ profissionais de Enfermagem \\ e dos pacientes em relação \\ aos toques experimentados. \\ O estudo foi desenvolvido \\ com 19 profissionais e 19 \\ pacientes, no periodo de \\ outubro a novembro de \\ 2000, através de observação \\ direta das interações e \\ entrevista individual. Os \\ sentimentos e percepções \\ relatados foram \\ categorizados e percebemos \\ que a maioria dos toques é \\ instrumental-afetivo.
}

\section{PALAVRAS-CHAVE}

Comunicação não-verbal. Toque terapêutico. Unidades de Terapia Intensiva.

\section{SUMMARY}

This study aims to identify the use of the instrumental and/ or emotional touch and its characteristics by nursing professionals in the nonverbal communication with the ICU and Semi Intensive Surgical Unit patients of a school hospital - University of São Paulo; and to identify the professionals and patients feelings and perceptions in relation to the touches experienced. The study was developed with 19 nursing professionals and 19 patients, from October to November 2000, through direct observation of the interaction and individual interview. The feelings and perceptions reported were classified and we noticed that most of the touches were instrumental-emotional.

\section{KEYWORDS}

Nonverbal communication. Therapeutic touch. Intensive Care Units.

\section{RESUMEN}

Este trabajo tiene como objectivo identificar la utilización, por los profesionales de Enfermería del toque instrumental y /o afectivo y sus características, en la comunicación no verbal con los pacientes de la UCIy unidad semiintensiva quirúrgica del HU-USP, y los sentimientos y percepciones de los profesionales de Enfermería y los pacientes en relación de los toques experimentados. Lo estudio fue desenvuelto con 19 profesionales y 19 pacientes, en el periodo de octubre a noviembre de 2000, por medio de observaciones directas de las interacciones y encuestas individuales. Los sentimientos y percepciones relatados fueram categorizados $y$ percibimos que la mayor parte de los toques fueran instrumental-afectivo.

\section{PALABRAS-CLAVE}

Comunicación no verbal. Tacto terapeutico. Unidades de Terapia Intensiva. 


\section{INTRODUÇÃO}

A comunicação é a base fundamental das relações interpessoais, inclusive na área da saúde, onde lidamos com pessoas, quer sejam elas nossas colegas de trabalho ou os pacientes que necessitam dos nossos cuidados. Ao estabelecer uma boa comunicação com os outros, contribuímos para a diminuição de conflitos e mal-entendidos, tornando as relações mais harmônicas e alcançando nossos objetivos com mais eficiência e satisfação.

Não podemos nos esquecer entretanto, que a comunicação vai muito além das palavras, sejam elas escritas ou faladas. A postura, os gestos, o olhar, o tom de voz e a maneira de tocar o outro são algumas das muitas maneiras que temos de transmitir e receber informações.

A percepção da comunicação e seu entendimento ocorre através dos órgãos dos sentidos, acrescidos de associações individuais que produzem significados para quem percebe. Essas associações e significados dependem diretamente do repertório de conhecimento individual, entendendo por isso, experiências vividas, crenças, valores, expectativas, enfim, sentimentos e pensamentos em que se envolve o indivíduo que está percebendo ${ }^{(1)}$.

As informações são emitidas de maneira verbal (os sons emitidos pelo aparelho fonador que fazem parte de um código lingüístico) e não-verbal (tudo que pode ter significado para quem emite ou recebe a mensagem, exceto as palavras por elas mesmas) ${ }^{(1)}$.

É a comunicação não-verbal que qualifica as relações e que pode complementar a verbal (quando auxilia a linguagem verbal na emissão da mensagem), contradizê-la (quando envia mensagem contraditória a expressa pela verbal), substituí-la (quando envia uma mensagem sem a utilização da verbal) e ainda demonstrar sentimentos do emissor, mesmo que este não tenha consciência disso ${ }^{(2)}$.

A tacêsica é o estudo do toque e das características que o envolvem, sendo elas o sexo e a idade dos comunicadores, a duração, localização, ação (velocidade e forma de aproximação que precedem o toque), intensidade (pressão exercida), freqüência e sensações provocadas pelo toque (graus de conforto e desconforto gerados nos agentes comunicadores) ${ }^{(1)}$.
O toque é um meio de comunicação nãoverbal que é essencial durante toda a vida do ser humano, transmitindo afeto, segurança e proteção. Na doença também pode significar apoio, amparo e valorização da pessoa ${ }^{(3-4)}$.

Apesar de o toque no cuidado ser um ato fisico, sabemos que ele pode transformar-se numa atitude de aproximação, de afeto, de solidariedade e de troca de emoções. Há relatos de experiência de perceber-se esse aspecto do toque principalmente com um paciente tetraplégico que, ao ser tocado por longo tempo na testa, apresentou dilatação pupilar, melhora da saturação de oxigênio e estabilização dos níveis tensionais ${ }^{(5)}$.

Desde 1988, existem estudos afirmando a importância de se usar o toque com mais consciência nas UTIs. Mesmo em pacientes com alteração de consciência, os sentidos da audição e tato podem não estar afetados. Através desses sentidos, então, é possível ter acesso a um indivíduo que, isolado em seu próprio mundo, necessita de comunicação com o meio externo ${ }^{(6)}$.

Diversos outros autores, em seus estudos sobre o uso do toque em pacientes graves, concluem que este pode funcionar como uma comunicação benéfica que proporcione conforto, segurança e satisfação ao paciente ${ }^{(6-8)}$. Foi constatado inclusive que o toque pode causar alterações de freqüência cardíaca e de pressão arterial nos pacientes ${ }^{(7,9)}$.

O contato físico provoca alterações neurais, glandulares, musculares e mentais e contribui para o restabelecimento dos pacientes hospitalizados ${ }^{(1,4)}$. O desamparo experimentado pelo paciente na situação de internação, quando há uma exacerbação das suas necessidades, é mais uma justificativa da importância do toque na área de saúde ${ }^{(1,8,10,11)}$.

Não são muitos, porém, os estudos de toque em unidades de terapia intensiva. Este estudo pretende apurar a ocorrência e os significados dos toques instrumental (decorrente da necessidade de desempenhar uma tarefa específica), afetivo (contato espontâneo que pretende demonstrar apoio, carinho e segurança) e instrumental-afetivo para pacientes e profissionais de Enfermagem de uma UTI e unidade semi-intensiva cirúrgica, conforme classificação de Silva ${ }^{(1)}$, Pearce ${ }^{(6)} \mathrm{e}$ Hudak; Galbo ${ }^{(8)}$.
Ocorrência e significado do toque entre profissionais de enfermageme pacientes de uma UTI e Unidade Semi-intensiva Cirúrgica 


\section{OBJETIVOS}

- Identificar a utilização, pelos profissionais de Enfermagem, do toque instrumental e/ou afetivo e suas características, na comunicação não-verbal com os pacientes da UTI e unidade semi-intensiva cirúrgica do HU;

- Comparar a freqüência e o tipo de toque utilizados por enfermeiros e auxiliares de enfermagem;

- Identificar a percepção e os sentimentos dos profissionais de Enfermagem em relação aos toques experimentados;

- Identificar a percepção e os sentimentos dos pacientes em relação aos toques experimentados.

\section{METODOLOGIA}

Tipo de Estudo: É um estudo descritivo, transversal e de campo.

Local do Estudo: O estudo foi desenvolvido na UTI e unidade semi-intensiva cirúrgica do Hospital Universitário da Universidade de São Paulo (HU-USP).

Amostra: Participaram do estudo 19 dos 32 profissionais de Enfermagem do quadro de funcionários da UTI e de unidade semiintensiva cirúrgica do HU - USP, dentre eles 6 enfermeiros e 13 auxiliares de enfermagem, e seus respectivos pacientes. Todos os participantes eram do sexo feminino, com mais de um ano de trabalho em UTI e tempo de formado variando de um a mais de 22 anos.

Procedimentos de Coleta de Dados: Inicialmente, foi solicitada autorização da Comissão de Ensino, Pesquisa e Ética da Instituição. Depois da autorização concedida, solicitamos aos profissionais e aos pacientes conscientes e que pudessem verbalizar, autorização para serem observados enquanto estivessem prestando cuidados e sendo cuidados, respectivamente, e para serem entrevistados posteriormente a essa $1^{\text {a }}$ fase de observação (Termo de Consentimento Pós-Informação, conforme modelo da instituição - HU).

Passos da Coleta de Dados: Fase 1: O método de pesquisa utilizado foi a técnica de observação direta não participante, onde os dados a serem observados não foram revelados antecipadamente aos elementos da uni- dade, evitando-se interferências no comportamento dos mesmos. Foi observada a maneira de tocar da equipe de Enfermagem e a reação dos profissionais e pacientes perante esse toque. As observações tiveram início no dia 23/10/2000, com término no dia $21 / 11 / 2000$. A escolha dos profissionais foi aleatória, seguindo a escala diária, e só participaram do estudo os pacientes que interagiram com esses profissionais durante o período de uma hora consecutiva, no início de cada plantão. Tais pacientes deveriam estar, necessariamente, conscientes, orientados e com possibilidade de verbalização. Foi observado um paciente/dia.Os seguintes aspectos foram registrados: identificação do profissional (primeiro nome, sexo, idade, categoria profissional e tempo de formado), tipos de toques realizados (instrumentais e/ou afetivos), duração dos toques, postura e olhar do profissional durante os toques, identificação do paciente (primeiro nome, sexo, idade e tempo de internação), movimentos corporais do paciente, expressões faciais do paciente e verbalizações de ambos.

Fase 2: Foram gravadas entrevistas com os profissionais de Enfermagem para constatar os sentimentos e sensações que vivenciaram quando realizaram os toques nos pacientes. As perguntas feitas foram: "O que é para você tocar um paciente numa UTI e unidade semi-intensiva?"; "Você sente alguma diferença nos toques, quando eles partem do paciente ou de você mesmo(a)?"

Fase 3: Foram gravadas entrevistas com os pacientes para constatar os sentimentos e sensações que vivenciaram quando tocados. As perguntas feitas foram: "Como o $\operatorname{Sr}(\mathrm{a})$ percebe o toque dos profissionais que é feito aqui na UTI?"; "Sentiu alguma diferença nos toques recebidos?".

Análise dos Dados: Os dados foram quantificados com relação ao tipo e características do toque e as respostas dos profissionais de Enfermagem e dos pacientes foram categorizadas segundo o tipo de percepção e sentimento relatados.

\section{RESULTADOS E DISCUSSÃO}

Para analisarmos as características dos toques, é necessário focarmos nossa atenção também em um fator que possui grande relevância no que diz respeito à comunicação 
não-verbal: a cinésica. Por cinésica entendemos a "linguagem do corpo", ou seja, a compreensão de que todos os movimentos e expressões corporais possuem um significado no contexto em que se apresentam e que podem ser decodificados por um observador atento ${ }^{(1,12)}$.

Neste estudo, classificamos a postura dos profissionais em relação aos pacientes em três categorias básicas: o eixo frente a frente, lateral e de costas. Dentre as expressões faciais, optamos por analisar o olhar do profissional durante sua interação com o paciente, classificandoo em: olha no rosto, olha no local do procedimento ou ausência de olhar. A Tabela 1 quantifica o número de toques instrumental, afetivo e instrumental-afetivo realizados pelos profissionais de Enfermagem, e a postura e o olhar destes profissionais durante as interações.

Podemos constatar através da Tabela 1, que os 6 enfermeiros observados (durante as 6 interações) realizaram ao todo 27 toques, o que nos dá uma média de 4,5 toques realizados por enfermeiro. Já os 13 auxiliares de enfermagem realizaram 162 toques, ou seja, 12,46 toques por profissional, quase 8 toques a mais que os enfermeiros (nas 13 interações observadas). Isso se deve ao fato de que nesta unidade o enfermeiro desenvolve muito mais atividades administrativas do que assistenciais, o que conseqüentemente diminui o número de toques realizados por eles.

Qualitativamente, não houve muita diferença entre os toques dos enfermeiros e dos auxiliares de enfermagem: a porcentagem de toques instrumentais foi de 7,41\% para ambos os profissionais; de toques afetivos foi de 7,41\% para enfermeiros e de $11,73 \%$ para auxiliares de enfermagem; e de toques instrumentais-afetivos foi de $85,18 \%$ para enfermeiros e de $80,86 \%$ para auxiliares de enfermagem.
Do total de 189 toques, 154 (81,48\%) foram instrumentais-afetivos, o que demonstra que a equipe de Enfermagem apesar de não dispor de muito tempo para dedicar atenção especial à cada paciente, aproveita o tempo utilizado na realização dos procedimentos para demonstrar apoio e carinho através dos toques.

Em relação à postura dos profissionais perante os pacientes, das 189 interações, apenas em uma, o que corresponde a $0,53 \%$, o profissional (auxiliar de enfermagem) posicionou-se lateralmente ao paciente, e nenhum se posicionou de costas. Podemos concluir que os profissionais, ao se posicionarem frente a frente com o paciente, tentam demonstrar verdadeiro interesse, facilitando assim a criação de um vínculo de confiança ${ }^{(6-7)}$.

Ao analisarmos os olhares dos profissionais perante os pacientes, constatamos que $115(60,85 \%)$ foram direcionados ao local do procedimento, $68(35,98 \%)$ ao rosto e houveram $6(3,17 \%)$ ausência de olhares. Apesar de os olhares no rosto serem os mais adequados, já que os vínculos verdadeiros envolvem o "olho-a-olho" e ser no rosto das pessoas que são expressos, de maneira não-verbal, seus pensamentos e sentimentos, a maior concentração de olhares voltados ao local do procedimento é perfeitamente compreensível, porque muitos dos procedimentos realizados pelos profissionais de Enfermagem exigem um nível de atenção muito elevado. Vale lembrar que podemos iniciar uma interação de cuidado olhando no rosto das pessoas e, depois, olharmos o local que exige nossa atenção.

Já a porcentagem de interações em que o profissional simplesmente não olhou para o paciente, é preocupante, na medida que o olhar é regulador do fluxo de conversação e que sua ausência denota falta de interesse
Ocorrência e significado do toque entre profissionais de enfermagem e pacientes de uma UTI e Unidade Semi-intensiva Cirúrgica

Tabela 1 - Tipo de toque, de postura e presença do olhar para o paciente, segundo categoria profissional. São Paulo, 2000

\begin{tabular}{|c|c|c|c|c|c|c|c|c|c|c|}
\hline \multirow{2}{*}{$\begin{array}{c}\text { Categoria } \\
\text { Profissional }\end{array}$} & \multicolumn{3}{|c|}{ Tipo de Toque } & \multirow{2}{*}{$\begin{array}{l}\text { Total de } \\
\text { Toques }\end{array}$} & \multicolumn{3}{|c|}{$\begin{array}{l}\text { Postura do } \\
\text { Profissional }\end{array}$} & \multicolumn{3}{|c|}{ Olhar Profissional } \\
\hline & TI & TA & TI & & $\mathbf{F} / \mathbf{F}$ & Late & Cost & Face & $\begin{array}{c}\text { Local } \\
\text { Proced }\end{array}$ & Ausente \\
\hline $\begin{array}{l}\text { Enfermeiro } \\
\text { Auxiliar de } \\
\quad \text { Enfermagem }\end{array}$ & $\begin{array}{c}2 \\
12\end{array}$ & $\begin{array}{c}2 \\
19\end{array}$ & $\begin{array}{c}23 \\
131\end{array}$ & $\begin{array}{c}27 \\
162\end{array}$ & $\begin{array}{c}27 \\
161\end{array}$ & $\begin{array}{l}0 \\
1\end{array}$ & $\begin{array}{l}0 \\
0\end{array}$ & $\begin{array}{c}6 \\
62\end{array}$ & $\begin{array}{l}20 \\
95\end{array}$ & $\begin{array}{l}1 \\
5\end{array}$ \\
\hline TOTAL & 14 & 21 & 154 & 189 & 188 & 1 & 0 & 68 & 115 & 6 \\
\hline
\end{tabular}

Legenda: $\mathrm{TI}=$ toque instrumental; $\mathrm{TA}=$ toque afetivo; $\mathrm{TIA}=$ toque instrumental e afetivo; $\mathrm{F} / \mathrm{F}=$ frente a frente; Later. = lateralizado; Local Proced. = local do procedimento. 
Tabela 2 - Tipo de verbalização entre profissional e paciente durante o toque, segundo categoria profissional. São Paulo, 2000

\begin{tabular}{lccccc}
\hline $\begin{array}{c}\text { Categoria Profissional } \\
\text { (Total) }\end{array}$ & F.I. & S.I. & F.E. & C.I. & C.O. \\
\hline $\begin{array}{l}\text { Enfermeiro (06) } \\
\text { Auxiliar de Enfermagem (13) }\end{array}$ & 2 & 2 & 1 & 18 & 1 \\
\hline TOTAL & 40 & 17 & 12 & 66 & 17 \\
\hline
\end{tabular}

Legenda: F.I. = Profissional fornece informações ao paciente; S.I. = Profissional solicita informações ao paciente; F.E. = Fala espontânea do paciente; C.I. = Conversa informal entre profissional e paciente; C.O. = Profissional conversa com outros.

pela continuidade da interação, podendo desmotivar o paciente, diminuindo sua confiança na equipe ${ }^{(1)}$. Normalmente, nessas interações, o profissional voltava seu olhar para o relógio ou para equipamentos que monitoravam os pacientes.

As verbalizações mais freqüentes foram $84(47,73 \%)$ conversas informais, seguidas de $42(23,86 \%)$ orientações dadas aos pacientes pelos profissionais. Chama a atenção que em $13(7,39 \%)$ verbalizações, foi o paciente que iniciou o diálogo. Além disso, a predominância das conversas informais demonstra uma característica muito específica da equipe de Enfermagem desta unidade que procurava, através de brincadeiras, deixar os pacientes à vontade, animando-os e proporcionandolhes alguns momentos de descontração.

Esse achado difere do estudo realizado por Noda, Poltroniere, Silva ${ }^{(13)}$ em pós-operatório de cirurgia cardíaca, pois as autoras encontraram maior número de verbalizações na categoria "solicita informações sobre as condições do paciente". Parece-nos que, nas UTIs, o controle sobre as condições do paciente é feito mais pelos monitores e observação direta, do que a partir do verbalizado por ele (mesmo em pacientes conscientes). A equipe pergunta muito pouco a ele sobre seu bem $\operatorname{estar}^{(8)}$.
Durante nossa observação, consideramos como resposta negativa do paciente ao toque, quando ele franzia as sobrancelhas, arregalava os olhos, tensionava a musculatura corporal ou tentava retirar a parte do corpo que estava sendo tocada. Quando uma dessas reações era observada, tentávamos categorizar qual a emoção que a motivara, primeiro pela própria impressão do observador e depois, confirmando a hipótese durante a entrevista.

Considerando a necessidade de identificar os sentimentos dos pacientes em relação aos toques recebidos, percebemos a importância de avaliar os fatores que pudessem interferir na sua reação ao toque, como os procedimentos realizados. Esses dados se encontram na Tabela 3.

Do total de 19 interações observadas, em $6(32 \%)$ delas percebemos sentimentos negativos em relação aos toques, sendo que em 5 ocasiões, eles foram decorrentes do procedimento que estava sendo realizado no momento: sentimento de angústia, apresentado em 2 momentos por um mesmo paciente que estava com uma severa insuficiência respiratória e que agravava-se durante sua mobilização pelos profissionais durante o banho no leito; a contrariedade de um paciente que estava tendo seus braços restritos porque insistia

Tabela 3 - Sentimentos negativos percebidos pelos pacientes, decorrentes do toque durante procedimentos. São Paulo, 2000

\begin{tabular}{lcccl}
\hline \multicolumn{1}{c}{$\begin{array}{c}\text { Sentimentos } \\
\text { Percebidos* }\end{array}$} & \multicolumn{2}{c}{ Tipo de Toque } & \multicolumn{1}{c}{$\begin{array}{c}\text { Procedimentos } \\
\text { Realizados }\end{array}$} \\
& TIA & TA & & \\
\hline Angústia & 1 & - & 1 & Banho no Leito \\
Contrariedade & 1 & 1 & - & $\begin{array}{l}\text { Restrição do Paciente } \\
\text { Medo }\end{array}$ \\
Dor & - & - & 1 & $\begin{array}{l}\text { Punção Venosa } \\
\text { Mudança de Decúbito + Punção de ponta de dedo }\end{array}$ \\
\hline
\end{tabular}


em tentar retirar os equipamentos nele fixados; o medo de um paciente quando foram puncionar sua veia; e a dor, em um paciente ao realizarem sua mudança de decúbito, e em outro ao picarem seu dedo para colher sangue para realização da glicosimetria.

Também encontramos um sentimento negativo (contrariedade) de um paciente que estava recebendo um toque afetivo. Como dito anteriormente, toque afetivo é aquele toque que é feito unicamente com o objetivo de demonstrar carinho, apoio e segurança ao paciente, durante o qual, não é realizado qualquer procedimento técnico específico ${ }^{(1,8,13)}$. Nesse caso, a reação desfavorável do paciente se deve ao fato de que há pouco ele havia tido os punhos restritos e uma profissional de Enfermagem tentava, justamente através deste toque afetivo, confortá-lo, enquanto explicava-lhe porque tinha sido necessário tomar essa atitude.

Como podemos perceber pela Tabela 4, o toque instrumental-afetivo foi o que teve uma média de duração maior, com 18,26s e 17,05s quando realizado por enfermeiros e auxiliares de enfermagem, respectivamente. A seguir, temos o toque instrumental com duração média de 13 s para os enfermeiros, quase o dobro do tempo médio de 7,33s dos auxiliares de enfermagem. O toque que teve menor tempo de duração para ambas as categorias e, o único em que os auxiliares de enfermagem tiveram média de duração maior que a dos enfermeiros $(5,57 \mathrm{~s}$ para $03 \mathrm{~s})$, foi o toque afetivo.

A partir de agora descreveremos as categorias encontradas nas falas dos profissionais e dos pacientes, conforme objetivos 2 e 3 deste trabalho.

Como dito anteriormente, as perguntas feitas durante as entrevistas dos profissionais de Enfermagem foram: "O que é para você tocar um paciente numa UTI e semi?"; "Você sente alguma diferença nos toques, a partir do paciente ou de você mesmo(a)?" A partir das respostas dos profissionais formulamos as seguintes categorias: 1) Tocar o paciente é...; 2) Por que tocar o paciente; 3) Fatores que influenciam o toque; 4) A diferença nos toques realizados; 5) Grau de dificuldade para realizar o toque; 6) A maneira de tocar; 7) Outros fatores valorizados na assistência além do toque; 8) Como enfrentar as dificuldades.

\section{Tocar o paciente é...}

Tocar o paciente, segundo os profissionais de Enfermagem, é algo natural e de grande importância que deveria ser feito tão corriqueiramente quanto dialogar com ele. Eles acreditam que o toque é um meio de se aproximar do paciente, proporcionando-lhe segurança, carinho e "calor humano, corroborando com o referido em literatura" ${ }^{(1,3,8,14)}$. Que o toque representa sentimento e que é possível através dele passar confiança e alcançar uma assistência de qualidade. Isto pode ser demonstrado pelos depoimentos a seguir:

"Tocar o paciente é dar segurança pra ele, é mostrar um cuidado com mais, é, com mais carinho e um cuidado individualizado, né?; “... é fazer o paciente sentir que eu estou do lado dele..."; “...é uma coisinha simples, mas de repente pode ser mais, transmite um certo calor humano, né?".

\section{Por que tocar o paciente}

Para os profissionais de Enfermagem desta unidade, a situação de hospitalização deixa o paciente muito fragilizado, com sentimentos de solidão e abandono, além de perceberem que a maioria tem muito medo de estar internado em uma UTI. Acreditam que, em um ambiente tão estranho e longe da família e amigos, os pacientes ficam extremamente dependentes da equipe de Enfermagem e que cuidar bem deles é extremamente recompensador.

Tabela 4 - Duração média dos toques, segundo categoria profissional. São Paulo, 2000

\begin{tabular}{|c|c|c|c|}
\hline \multirow[b]{2}{*}{ Categoria Profissional } & \multicolumn{3}{|c|}{ Duração Média dos Toques (em segundos)* } \\
\hline & TI & TA & TIA \\
\hline Enfermeiros & 13 & 03 & 18,26 \\
\hline Auxiliares de Enfermagem & 7,33 & 5,57 & 17,05 \\
\hline MÉDIA TOTAL & 8,14 & 5,33 & 17,23 \\
\hline
\end{tabular}

Legenda: $\mathrm{TI}=$ toque instrumental; $\mathrm{TA}=$ toque afetivo; $\mathrm{TIA}=$ toque instrumental $\mathrm{e}$ afetivo.

* controle feito em relógio cronômetro

Ocorrência e significado do toque entre profissionais de enfermagem e pacientes de uma UTI e Unidade Semi-intensiva Cirúrgica 
Para eles, o toque é feito de maneira insuficiente no hospital e afirmam que através dele podemos transmitir carinho, segurança, confiança e estímulo para o paciente. Que ninguém melhor do que um profissional de Enfermagem, que está sempre tão próximo do paciente, para realizar esse cuidado, como referem outros autores ${ }^{(8-9)}$. Afinal, segundo eles, todas as pessoas precisam de toque e nós, brasileiros, "adoramos tocar". É possível conferir essas crenças pelas falas a seguir:

"Eu acho assim, que o hospital é muito frio, sabe? Falta muito isso no hospital, sabe? Mais carinho mesmo."; "...ele tá, com certeza, desprotegido, né? Tá sem familiar, tá sem ninguém perto, por mais que você seja amigo, você não é essa pessoa que ele queria que tivesse ali."; "O toque faz parte, a mão, você trabalha muito com as mãos. O profissional de enfermagem trabalha muito com a mão."

\section{Fatores que influenciam o toque}

Os profissionais de Enfermagem enumeram diversos fatores que dificultam e facilitam o toque. Eles afirmam ter receio de tocar pessoas do sexo oposto e que, quando o procedimento a ser realizado é muito invasivo ou quando a parte do corpo a ser tocada é muito íntima, o toque pode causar constrangimento tanto para eles quanto para os pacientes, como pode ser observado pelo depoimento:

“...dependendo da parte do corpo que você toca...é um pouco invasivo... Você mexe muito com os sentimentos daquela pessoa...até eu fico um pouco constrangida."

Além disso, afirmam que o estado de espírito do profissional tem muita influência na sua maneira de tocar:

"E eu acredito sim que varia de acordo com o meu estado de espírito também. Naqueles dias em que você, em que eu, por exemplo, acordo mais carente, eu acho que eu consigo tocar mais, sabe? Aquilo que, você dá aquilo que cê tá precisando."

Referem que em pacientes muito agressivos, ou que exigem uma atenção especial da equipe, não permitindo que ela cuide dos outros pacientes, é mais difícil tocar. Alguns acreditam que não tocar o paciente é respeitar a vontade dele, outros admitem ser seu mecanismo de defesa: “...não avanço se o paciente não permitir...Então assim, se ele quer ficar sossegado, tranqüilo, eu faço o possível pra não incomodar, né?"

Para outros, a capacidade de tocar está intimamente ligada ao envolvimento que há entre o profissional e o paciente:

"...eu tenho uma facilidade muito grande pra me apegar aos pacientes...eu tenho um carinho muito grande, parece que faz tempo eu já conheço aquela pessoa, entendeu? Então, assim, dentro de mim eu sinto que eu gosto dele sem nunca ter conhecido."

\section{A diferença nos toques realizados}

A maioria dos profissionais de Enfermagem acha que existe diferença em sua maneira de cuidar, inclusive nos toques que realiza nos diferentes pacientes, como comprovam os depoimentos:

"Pode ser mais difícil como pode ser mais fácil, dependendo do tipo do paciente."

"...é mentira dizer que a gente gosta e se afeiçoa a todos de maneira igual, né?"

Outros poucos afirmam que seus toques são sempre iguais:

"Pode o paciente tá grave, pode ficar um mês, dois, três, eu cuido do mesmo jeito que cuido do que chegou ontem, do bonito, do feio, do pobre, do rico, eu não tenho dificuldade...Não me canso dele."; “...não diferencio nenhum, pra mim todos eu tento ter o mesmo carinho, tocando sempre também."

\section{Grau de dificuldade para realizar o toque}

Os profissionais de Enfermagem afirmam que com pacientes que aparentam maior fragilidade, como os idosos, crianças, pacientes que permanecem muito tempo internados, e com pacientes mais graves, o profissional cria um laço de afeição que propicia o acontecimento espontâneo do toque:

“...geralmente toco os pacientes que eu me afeiçôo mais, que mexem mais comigo, né? São geralmente pacientes que demonstram muita fragilidade. São esses que estão muito tempo com a gente e que você vê claramente que eles tão lá sofrendo, sofrendo, lutando, sofrendo, então a cada queda deles, a cada piorada que eles dêem, isso faz com que a gente chegue, com que eu chegue mais perto, né? Pra dar força mesmo.." 
“...no idoso, eu sinto vontade mais de tocar, dá carinho, porque eu acho que ele sente falta. Na criança..."

"Principalmente esses pacientes mais graves, né?"

Afirmam que existem pacientes que são mais difíceis de tocar, citando novamente os pacientes agressivos, além dos pacientes que recusam o tratamento ou que podem ter alguma reação inesperada:

"Tem paciente que...não é que ele seja arrogante, talvez ele seja mais sofrido, então ele não sabe nem direito o que ele quer..."

\section{A maneira de tocar}

Quase todos os profissionais, como o

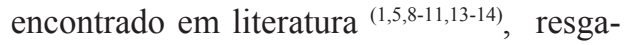
tam a importância da empatia, e concordam que é importante colocar-se na posição do paciente para assim saber qual a maneira mais adequada de tocá-lo:

"Antes de tudo, é se colocar no lugar dele, né?...antes de tudo, calor humano..."

"Tocar de um jeito que eu gostaria de ser tocada."

Também acreditam que fatores como seu estado pessoal e a receptividade do próprio paciente podem empobrecer os toques, em qualidade:

“...a gente sente, percebe uma diferença maior quando o paciente está agressivo. Nós não tocamos o paciente agressivo com mãos de seda, como costumamos tocar os pacientes mais calmos."

"Então, as vezes, você toca assim meio de qualquer jeito no doente, sabe? Você tá um pouco sem paciência, então você, você vai pôr um termômetro de qualquer jeito, você pega, fala de qualquer jeito, assim, não agressivo, mas não com aquela... do jeito que você deveria."

\section{Outros fatores valorizados na assistência além do toque}

A maioria dos profissionais afirma que, além do toque, é importante estar atento a outros fatores que podem ser até mais importantes, dependendo da situação:

“...as vezes não precisa nem de tocar, só da gente se aproximar, dar atenção e se fazer presente já, já ajuda bastante.”;
"Não só o toque com a mão, mas também o toque através das palavras, tá conversando, tá aliviando..."; "...as vezes, um prender de cabelo, um esticar de lençol já conforta bastante."

\section{Como enfrentar as dificuldades}

Os próprios profissionais tem consciência de que, muitas vezes, seus problemas pessoais interferem em sua vida profissional, e eles mesmos tentam procurar novas formas de lidar com essas dificuldades que surgem a cada dia:

"O paciente não tem culpa se minha casa não tá bem, né?, se a minha vida lá fora não tá bem...não misturo as estações."; "...quando eu percebo que eu tô colocando coisas minhas que eu acho que eu não deveria, eu já corto, sabe?"

Pelo conjunto das respostas obtidas, ficou clara a importância e a consciência que essa equipe de Enfermagem têm com relação ao toque. Como os profissionais foram observados antes das perguntas, podemos afirmar que é coerente a linguagem verbal e seu não-verbal sobre esse tema, pois expressam das duas maneiras, complementarmente, esse valor.

A partir de agora, registramos as respostas dos pacientes sobre este tema. Como dito anteriormente, as perguntas feitas durante as entrevistas dos pacientes foram: "Como o $\operatorname{Sr}(a)$ percebe o toque que é feito aqui na UTI?"; "Sentiu alguma diferença nos toques recebidos?". A partir das respostas dos pacientes, formulamos as seguintes categorias: 1) Percepção dos pacientes em relação ao toque; 2) As diferenças entre os toques recebidos; 3) Percepção sobre a equipe de Enfermagem; 4) A profissão Enfermagem de uma maneira geral.

\section{Percepção dos pacientes em relação ao toque}

A maioria dos entrevistados demonstra satisfação perante os toques experimentados, como demonstram os depoimentos:

\section{"É o mesmo que família, eu tô admirada..."; "O toque aqui é, é ótimo."; "Em geral é bom. Eles fazem com bastante cuidado."}

Alguns poucos pacientes se expressaram de maneira ambígua, mas denotando uma evidente contrariedade e insatisfação com os toques recebidos, como evidencia a fala:
Ocorrência e significado do toque entre profissionais de enfermageme pacientes de uma UTI e Unidade Semi-intensiva Cirúrgica 
"É, as vezes é ruim, né? Mas todo toque é bom, falá o quê?"

\section{As diferenças entre os toques recebidos}

Alguns poucos pacientes não perceberam, ou preferiram não comentar, as diferenças entre os toques recebidos, como percebemos pelo relato:

"Quase todos os jeitos de pegar eram quase iguais."

Os pacientes que afirmaram existir diferenças entre os toques realizados, demonstraram naturalidade quanto a isso, porém não souberam explicar bem essa distinção, como percebemos pelos depoimentos a seguir:

"Que em uns que tem mais, é, mais jeito pra tocar na gente, pra cuidar da gente. Outros já não, né?"; "...tem uns que têm a mão mais pesada, mas não é pelo querer deles. Acho que é a mão mesmo, tem outros que têm a mão mais leve."; "Tem enfermeiras que dá uma injeção que você nem sente, né? E tem uns que é fogo, né? Arranca a bunda da gente!"

Apesar de serem de sexos diferentes (11 homens e 8 mulheres), os pacientes não fizeram nenhuma referência a serem cuidados só por mulheres (na Enfermagem) como estava ocorrendo naqueles dias. Sabemos que existem diferenças com relação à aceitação do toque por homens e por mulheres (as mulheres aceitam com mais naturalidade o toque espontâneo) ${ }^{(3)}$; porém esse aspecto não aflorou neste estudo. Podemos inferir que, talvez por ser uma unidade que abriga pacientes mais críticos, o toque nesse local seja aceito com mais naturalidade por ser necessário à sobrevivência de todos eles.

\section{Percepção sobre a equipe de Enfermagem}

Durante as entrevistas, mesmo o foco sendo o "toque", os pacientes manifestaram diferentes opiniõ es em relação ao desempenho da equipe de Enfermagem no seu todo (leram toque igual cuidador) que, em sua grande maioria, foram favoráveis:

"É, carinho, respeito e muita dedicação que eles têm à profissão deles."

“...qualidade extra de aproximação de samaritanos...demonstram interação, preocupação e dedicação espontâneas..."
Entretanto, alguns pacientes expressaram opiniões desfavoráveis, que demonstravam certo desagrado com alguns membros da equipe de Enfermagem:

"Tem umas pessoas que é muito bom, mas tem umas que não dá! Hoje mesmo pedi um papel pra uma enfermeira aqui e ela fez de conta que não escutou e foi embora pra lá. Agora, as outras, sai de lá e vem e arruma tudo. Por que ela, que uma, não pode fazer que nem as outras? Eu acho assim, tem que agir tudo igual."

"...as vezes eu peço água, por exemplo, e demora 2 ou 3 vezes pra me atender. Não é uma revolta, mas eu notei isso não sei porquê. Como eles são tão eficientes nas outras partes, e isso aí que é uma coisa simples não é atendida prontamente."

A profissão Enfermagem de uma maneira geral

Nessa categoria fica visível a importância do toque para o cuidar do paciente, pois eles acabaram fazendo uma reflexão da própria profissão a partir das perguntas feitas. Conceitos sobre a Enfermagem foram relatados durante as entrevistas, todos eles associados ao lado altruísta e humanitário da profissão, mas também ao lado científico de conhecimento e qualificação elevados:

"Trabalho insano!"; "...trabalho de sacrifício a Enfermagem.”; “...a Enfermagem exige dedicação e empenho.”; “...pra trabalhar nesse trabalho aí , precisa pessoa capacitada mesmo, né? Que se não, não trabalha."

\section{CONCLUSÃOE CONSIDERAÇÕES FINAIS}

Foi encontrado um total de 189 toques, em 19 interações observadas, sendo 27 toques provenientes de 6 enfermeiros, e 162 de 13 auxiliares de enfermagem. A maioria deles (154) foi do tipo instrumental/ afetivo. A postura do profissional para tocar o paciente foi frente a frente em 188 dos toques. O profissional olhou para a face do paciente 68 vezes, para o local do procedimento 115 vezes e não olhou para o paciente (apesar de tocá-lo) 6 vezes.

Os resultados encontrados em relação à duração média dos toques instrumental e instrumental-afetivo sugerem que a diferença entre simplesmente realizar um procedimento 
(toque instrumental) e realizá-lo com carinho (toque instrumental-afetivo) é de pouco mais de 5segundos para os enfermeiros (de 13 para 18,26 s) e de pouco menos de 10 s para os auxiliares de enfermagem (de 7,33 para17,05). Além disso, de acordo com a média de duração dos toques afetivos encontrados neste estudo ( 3 a $5,57 \mathrm{~s}$ ), é importante repensarmos se não seria realmente possível reservarmos mais de 03 a 06 segundos, por paciente, para demonstrarmos que nos importamos e que ele pode contar conosco.

Os profissionais participantes do estudo, em geral, parecem entender a importância do toque e realizá-lo sempre que possível. Acreditamos que se eles prestarem ainda maior atenção na maneira de interagir com os outros e nas reações que provocam, conseguirão superar muitas das dificuldades que referem enfrentar ao realizar os toques. O limite do toque é único para cada relação.
Quanto aos pacientes, a maioria deles parece estar satisfeita, não somente com os toques, mas com o atendimento em geral que recebem. É importante ressaltar que durante as entrevistas vários deles ficavam constrangidos e receosos de serem ouvidos, apesar de esclarecidos quanto a liberdade que tinham de expressar suas opiniões com sinceridade. Os pacientes precisam conscientizar-se da importância que tem sua crítica, como usuários dos serviços que oferecemos, para nosso aprimoramento e desenvolvimento contínuos.

Gostaríamos de ressaltar que os resultados encontrados neste estudo mostram que uma UTI não necessariamente é um "lugar frio" e que é possível encontrar profissionais tão humanos e envolvidos com esse compromisso, que é comum a todos nós, da área de saúde: cuidar!

\section{REFERÊNCIAS}

(1) Silva MJP. Comunicação tem remédio: a comunicação nas relações interpessoais em saúde. São Paulo: Gente; 1996.

(2) Silva MJP. Análise comparativa da aplicação de um programa sobre comunicação não-verbal para enfermeiros hospitalares. [livre docência] São Paulo (SP): Escola de Enfermagem da Universidade de São Paulo, 1998.

(3) Montagu A. Tocar - o significado humano da pele. São Paulo:Summus; 1988.

(4) Davis PK. O poder do toque. São Paulo: Best Seller; 1991.

(5) Bettinelli LA, Erdmann AL. Cuidado solidário: um compromisso social da enfermagem em unidades de terapia intensiva. Cogitare Enferm 1998;3:23-33.

(6) Pearce J. The power of touch. Nurs Times $1988 ; 84: 26-9$

(7) Lynch JJ. The simple act of touching. Nurs 1978; 8:32-6.

(8) Hudak CM, Gallo BM. Cuidados intensivos de Enfermagem. Rio de Janeiro: Guanabara Koogan; 1997. A dinâmica do toque no cuidado ao paciente; p. 39-50.
(9) Palma M, Silva D. O efeito da comunicação táctil na satisfação dos doentes relativamente aos cuidados de enfermagem no pós-operatório imediato de cirurgia cardíaca. Servir 1994; 40:226-45.

(10) Pinto CMS, Rocha EA, Silva MJP. O toque como elemento da comunicação parturiente/ enfermeiro obstetra durante a assistência no pré-parto. Nurs 2002; 47:31-4.

(11) Queijo AF, Silva MJP. O significado do toque na visão dos profissionais que prestam assistência direta em uma unidade de terapia intensiva neurológica. Âmb Hosp 2001; 149: 25-30.

(12) Birdwhistell RL. Kinesis and context. Philadelphia: Pennsylvania Press; 1970.

(13) Noda KS, Poltronieri MJA, Silva, MJP. Análise de fatores proxêmicos em situação de pós-operatório. In: Anais do II Congresso Brasileiro de Enfermagem em Centro Cirúrgico 1995; jun. São Paulo: SOBECC; 1995. p.3-10.

(14) Sovenhi RM. A importância da comunicação que tem sua gênese no toque [monografia] São Caetano do Sul (SP): UniABC, 1998
Ocorrência e significado do toque entre profissionais de enfermageme pacientes de uma UTI e Unidade Semi-intensiva Cirúrgica 